\title{
Women's Perceptions About Mobile Health Solutions for Selection and Use of Family Planning Methods in Karachi: A Feasibility Study
}

Farina Abrejo ( $\sim$ farina.abrejo@aku.edu )

Aga Khan University

Romaina lqbal

Aga Khan University

\section{Sarah Saleem}

Aga Khan University

\section{Research Article}

Keywords: mHealth, mobile health, Family planning, Low socio-economic areas, the feasibility of family planning, acceptability of family planning, Low and middle-income countries

Posted Date: January 18th, 2022

DOI: https://doi.org/10.21203/rs.3.rs-1245872/v1

License: (9) (1) This work is licensed under a Creative Commons Attribution 4.0 International License. Read Full License 


\section{Abstract \\ Background}

The qualitative study explored the feasibility and acceptability of potential mHealth intervention from women living in low socio-economic areas to increase the uptake of family planning. The study also discussed the potential benefits of mHealth intervention by exploring providers perceptions as well.

\section{Methods}

The qualitative exploratory study recorded the perception of 23 women and seven in-depth interviews with the providers of family planning services. These interviews asses women's attitude though; personal experience based on the usage of smartphones and family planning, acceptability for personal benefits, features of mobile application and the convenient language, and self-efficacy for identifying the potential impact of mHealth intervention to increase women's empowerment for family planning usage.

\section{Results}

Three predetermined themes were used to record the perception of women. The personal experience of women identified that women in low-socio economic areas use mobile phone frequently, they use phone to get preventive information for healthcare. Few women have experience using mobile phones for getting information about sexual and reproductive health. Women considered; poor counselling and high transport costs to the facilities, as major barriers to getting family planning services. Perceived acceptability discussed the potential features of the mHealth app. Women considered including short videos instead of written material will help them to understand its usage, complete information about family planning method including; dosage, expected side effects and potential benefits suggested to include in the app. Women perceived that the mHealth intervention will save women's cost of transport to the facility and will fill the information gap about family planning methods. While providers considered that it will save their time in counselling and motivating women for the method at the facility. Self-efficacy in the form of women empowerment in deciding family planning was one of the major factors discussed, where women discussed that the mHealth intervention will increase their self-confidence to discuss the method with their husbands.

\section{Conclusion}

There is a high potential for mHealth interventions for family planning in Pakistan. The usage of mobile phones can be utilized for increasing women's acceptability and accessibility for family planning uptake in the country.

\section{Introduction}

"Mobile Health or mHealth" comes under the umbrella of eHealth, which can be defined as "the use of mobile and wireless communication technologies to improve the healthcare delivery, outcomes and research" (1). More than $60 \%$ of the population in low and middle-income countries (LMICs) use mobile phones in healthcare for 
diagnostic, monitoring, health reporting, and surveillance etc (2). There is a strong link between mHealth intervention with patient-centred care, which is considered the core process of empowerment $(3,4)$. The study by Oxford University mentioned that mobile phone usage increases women's empowerment among LMICs as it provides better information about sexual and reproductive health, which helps women to decide on their own about their sexual life (5). Further, it also increases self-efficacy, which is an essential factor to achieve empowerment, and also one of the positive outcomes of digital interventions (6).

A person-centred approach in sexual and reproductive health, especially in family planning, is crucial to bring empowerment among women (7). Using mHealth to increase knowledge and uptake of modern contraceptives has been considered one of the cost-effective interventions in the world (8), especially for LMICs, where it is used to change behaviour and increase uptake of modern contraceptives (9). There are several single or combined mobile phone interventions, such as text messages, voice messages, videos and applications that are used as an alternative or adjunct to face-to-face family planning services to increase uptake of family planning in the LMICs (10). These interventions could easily be utilized in Pakistan, where $75 \%$ of the population own mobile phones (11). Despite the high penetration of smartphones (51\% in 2020) (12), there is a lack of utilizing mHealth for preventive health services in the country field(13). On the other hand, the usage of modern contraceptives is as lower as $25 \%$, and only $19 \%$ of women get information about; side-effects, its management, and information about other methods, 3 out of 10 women discontinue the family planning method within 12 months and one-third (33\%) of currently married women have an unmet need of family planning in Pakistan (14).

A study to understand the feasibility of mHealth for improving uptake of antenatal and post-natal services in Pakistan identified that women and providers are willing to use mHeatlh for these services because they considered it "more beneficial than face-to-face communication" (15). Other LMICs incorporated users' suggestions to develop mHealth intervention to increase knowledge and improve individual sexual and reproductive health outcomes. Applications such as m4RH in Cambodia. (16), iMACC (Mobile Application for Contraceptive Choice) in Kenya(17), and in Sierra Leone for connecting the young population for family planning services are among those successful interventions. Pakistan also experimented mHealth to increase the capacity of healthcare providers such as Lady Health Workers (LHWs) through the mobile application Roshan Mustaqbil (Bright Future), where training on education and counselling on reproductive, maternal, newborn and child health (RMNCH) services in Sindh is provided to LHWs (18). Exploring the acceptability of mobile health intervention among women or users is also important to fill the gap of low contraceptive usage in the country. According to the mobile gender gap report of 2020 (19), the gender gap for mobile internet is narrowing in LMICs where $54 \%$ of the women are using mobile internet.

To understand the current need for family planning that can be addressed through a mobile phone application; this study explored the perception of women for acceptability and feasibility of the family planning application that will provide required information and knowledge that women need to accept the contraceptive method. The study explored experiences and perceptions of married women of reproductive age (18-49 years) regarding the role of mHealth intervention for family planning information. The study also investigates the perception of providers (community health workers and doctors who provide family planning services) to understand the design and content of application that could work the best way to support women for uptake of family 
planning. The study also discussed the potential of mobile phone applications for increasing family planning uptake among users with the providers, where the expected challenges and facilitating factors were explored.

\section{Methods}

\section{Study Design}

A qualitative exploratory study design was used to understand the perception of women regarding the feasibility and acceptability of using mobile applications to increase uptake of family planning. A total of 23 semi-structured in-depth interviews were conducted with women of age 15-49 years. These interviews explored the current usage of family planning among women and also identified the attitude of women toward mobile phone usage. The future intention of women to use mobile phone applications for increasing uptake of family planning was also explored. Furthermore, the preference of women for mobile applications including language, features and the information of family planning that needs to be included in the application was also discussed during these interviews.

Seven in-depth interviews were additionally conducted with the providers (doctors, lady health visitors and nurses) of family planning services. The purpose of conducting these interviews was to record the insight of these providers for the current need of family planning among women, their perception about how women can use mobile phone applications for family planning and understand the perceived impact of mobile phone applications on family planning services.

\section{Study Setting}

The study was conducted in two sites; Azam Basti and Gadap Town of Karachi from May 2020-July 2020. Azam Basti is located in North East Karachi and has an approximate population of 120000 . There is a diverse population in Azam Basti, but the majority is the Christian community living in this area. While Gadap Town is situated in the North West Karachi with around 300,000 people. Most of the people belong to the Baloch community in Gadap Town. The purpose of selecting these areas is to understand the feasibility and acceptability of mobile phone applications for family planning among women living in low socio-economic areas, which have limited accessibility of family planning services and the gaps within these services are high.

\section{Study recruitment and sampling}

The field staff recruited women of reproductive age (15-49 years). Inclusion criteria involve the woman who has been used or currently using family planning and either the owners of smartphones or uses their husband's phone. The family planning providers recruited for this study who have been providing family planning services for the last more than two years in the same area as these providers had a better understanding of local women using mobile phones and the potential of using mobile applications for family planning in the future. All the indepth interviews were conducted till the time of thematic saturation, which means no new data or theme emerged from the interviews $(19,20)$.

\section{Theoretical Framework of the study:}


To understand the acceptance and feasibility of mobile applications for family planning among users, it is important to record the intention of individuals towards the mobile app to increase knowledge and understanding of family planning. The study identified current/previous practices for family planning usage and usage of smartphones. It helped to understand what factors motivate women to use family planning, and also identified reasons for leaving the family planning methods. On the other hand, mobile phone usage consists of their preferred applications and features were also explored in this domain. The second important factor was the acceptability and feasibility of mobile applications for family planning among women of reproductive age. The factors that need to be considered while developing the application, including language, features etc. The third domain was self-efficacy. Empowerment, which produces a high probability of specific behaviour is the result of the self-efficacy (22). In this research, empowerment is considered as women's behaviour towards deciding family planning. The perception of women was recorded for self-efficacy in the form of empowerment. Figure 1 describes the factors this study identified under personal experience, acceptability and self-efficacy.

\section{STUDY PROCEDURE}

After the identification of participants, field staff gave a brief introduction of the study to the women. The date and time for the in-depth interview were set after participants consent. The written consent was obtained from participants who can read and write, while for those who are not educated, a thumb impression was obtained. The study purpose and procedure was explained to all the participants at the beginning of the study, before consent. When the participants agreed to be part of this study, consent was obtained. The attitude of women was assessed in two areas; usage of smartphones, which includes timings and features of mobile phones that women used frequently, and current usage of family planning also explored with the questions about decision making for family planning method, availability of family planning services, problems related to the accessibility of the services, and the information provided to the women at the time of services delivery. Acceptability and feasibility were assessed through inquiries related to potential features and preferred language of the family planning application, the kind of information women considered important to be included in the application, as well as the perceived benefit was also explored through the semi-structured guideline. Finally, the self-efficacy of women for using the family planning application independently and perceived contribution of the application towards women empowered was identified through questions related to the potential benefit of the application on women's life. Similarly, the in-depth interviews with providers identify perceived attitude, feasibility and self-efficacy of women who visit the family planning facilities.

\section{DATA ANALYSIS:}

The data was transcribed from the local language (Urdu) to English. NVivo 11, a qualitative data analysis software was used for coding. As the study framework had predetermined themes, a deduction approach was followed for data analysis. The following steps were used for analysing the data:

The first step was thematic content analysis, where predefined broader themes of attitude, perceived norms and personal agency were further verified, confirmed and qualified with the help of two researchers who were involved in 'open coding'. The words or summary of each phrase were identified and the information which is "off the topic" was recognized. The second step was to identify duplication and cross out information, which helps to recognize similar categories. The list of final categories was compiled. Specific colour codes were 
given to each category and information related to those specific categories were separated and summarized. (Table 1 is showing themes and categories). 
Table 1

Themes, sub-themes, categories and codes

Theme 1: Personal experience

\begin{tabular}{|c|c|c|}
\hline Sub-theme & Categories & Codes \\
\hline \multirow[t]{4}{*}{ Mobile phone usage } & Features & $\begin{array}{l}\cdot \text { SMS } \\
\cdot \text { Videos } \\
\text { - Internet searching } \\
\text { - Calls } \\
\text { - Voice messages }\end{array}$ \\
\hline & Applications & $\begin{array}{l}\text { - WhatsApp } \\
\text { - Youtube } \\
\text { - Tiktok } \\
\text { - Facebook }\end{array}$ \\
\hline & Timings & $\begin{array}{l}\cdot \text { Morning } \\
\cdot \text { Evening }\end{array}$ \\
\hline & For Health & $\begin{array}{l}\text { - COVID-19 information } \\
\text { - Home remedies for diarrhoea } \\
\text { - Irregular manustral cycle } \\
\text { - Sexual health issues } \\
\text { - Contact doctors through mobile phone }\end{array}$ \\
\hline \multirow[t]{2}{*}{ Family Planning usage } & $\begin{array}{l}\text { Reason for using family } \\
\text { planning }\end{array}$ & $\begin{array}{l}\text { - Space between children } \\
\text { - Don't want more children } \\
\text { - Malnourishment } \\
\text { - Poverty }\end{array}$ \\
\hline & $\begin{array}{l}\text { Reason for not using } \\
\text { family planning }\end{array}$ & $\begin{array}{l}\text { - Side effects } \\
\text { - Want to have a son }\end{array}$ \\
\hline
\end{tabular}

\section{Theme 2: Acceptability of mobile application}

Perceived benefit for Provide information and women
- Family planning method

- Side effects and how to manage them

- Address misconceptions 


\section{Theme 1: Personal experience}

\begin{tabular}{|c|c|c|}
\hline & \multirow[t]{3}{*}{ Cost-effectiveness } & - Travelling cost \\
\hline & & - Doctor's fee \\
\hline & & - Fee for side effect management \\
\hline \multirow{4}{*}{$\begin{array}{l}\text { Features for mobile } \\
\text { application }\end{array}$} & Language & - Local language (Urdu) \\
\hline & \multirow[t]{3}{*}{ Features } & - Videos \\
\hline & & - Pictures \\
\hline & & - Voice recordings \\
\hline \multirow{6}{*}{$\begin{array}{l}\text { Information about } \\
\text { family planning }\end{array}$} & \multirow[t]{4}{*}{ Family planning method } & - Usage \\
\hline & & - Side effects \\
\hline & & - Advantages \\
\hline & & $\begin{array}{l}\text { - Information about misconceptions related to the } \\
\text { method }\end{array}$ \\
\hline & \multirow[t]{2}{*}{ Other information } & - Infertility \\
\hline & & - Family planning facilities addresses \\
\hline \multirow{4}{*}{$\begin{array}{l}\text { Perceived benefits for } \\
\text { providers }\end{array}$} & & - Save the time of counselling \\
\hline & & $\begin{array}{l}\text { - Women will have all the information on side } \\
\text { effects }\end{array}$ \\
\hline & & -Women already know out the potential benefit \\
\hline & & - More women can be served \\
\hline \multicolumn{3}{|l|}{ Theme 3: Self-efficacy } \\
\hline \multirow[t]{3}{*}{ Increase empowerment } & & $\begin{array}{l}\text { - Women can make the decision on their own for } \\
\text { family planning method }\end{array}$ \\
\hline & & $\begin{array}{l}\text { - Dependency on community workers and providers } \\
\text { will be reduced }\end{array}$ \\
\hline & & -Increase self-confidence \\
\hline
\end{tabular}

\section{Results}

A total of 30 in-depth interviews were conducted among which 23 were married women of reproductive age living in the selected sites and seven were family planning providers including; LHVs $(n=4)$, doctors $(n=1)$ and Family Welfare Workers $(n=2)$. (Table 2$)$. The majority of respondents own a smartphone $(n=18)$, the rest were using their husband's mobile phones. 
Table 2

Respondents characteristics

\begin{tabular}{|lll|}
\hline Characteristics & Women of reproductive age & Family planning providers \\
\hline Age, years & & 1 \\
\hline $18-27$ & 5 & 4 \\
\hline $28-37$ & 11 & 2 \\
\hline $38-47$ & 7 & \\
\hline Education & & - \\
\hline No Schooling & 5 & - \\
\hline Grade 1-5 & 3 & - \\
\hline Grade 6-10 & 7 & 4 \\
\hline Intermediate & 5 & 3 \\
\hline Bachelors & 3 & \\
\hline Working experience & - & 3 \\
\hline $1-10$ years & - & 4 \\
\hline $11-20$ years & 13 & 2 \\
\hline Number of Children & - & 3 \\
\hline No children & 10 & 2 \\
\hline $1-3$ children & -6 children & 13 \\
\hline
\end{tabular}

Three predetermined themes were used for exploring the perception of women for mobile application, $(I)$ personal experience based on using mobile phones and currently or previously used family planning methods, (2) acceptability is the perception of respondents about the features and information that considered important and acceptable to include in the application and (III) self-efficacy which focused on the empowerment that women will expect to achieve by using the mHealth intervention.

I. Personal Experience: The semi-structured guide inquired about mobile phone usage and experience related to the family planning method with women. Following sub-themes and categories emerged from the data.

Mobile phone usage (application that women use). This sub-theme identified the high usage of mobile phones among those respondents who own smartphones (5-6 hours) than those who use their husband's phone (1-2 hours). The timings of using the mobile phone were also different among these respondents; owners use it in the morning and the evening, while women who use the mobile phone of their husband use it in the evening only. All women were well aware of mobile applications and their usage, almost all of the women use 
WhatsApp (messenger app). The major reason for using this app is that it's free, voice messages can be sent easily, and files can also be shared.

'I use WhatsApp because it is free, many of my friends share videos and photos through this application $(A$ woman living in GadapTown).

\section{Mobile phone usage for health}

Most of the respondents mentioned that they use the phone to search for prevention against Coronavirus these days. Women also discussed using mobile phones to search for home remedies for diarrhoea, headache, flu or fever, as well as they also search for chronic diseases such as arthritis, diabetics and heart diseases.

'My children mostly become sick with diarrhoea, so I sometimes search for home remedies to treat diarrhoea, and it does work' (A woman from Azam Basti)

'I watch YouTube videos to see prevention and treatment of diabetics and arthritis because my mother has these diseases' (A woman from Azam Basti)

A few women discussed using smartphones for getting information about the issues related to sexual health such as irregular menstrual cycles and heavy bleeding during menstrual. The major reason for searching for these topics is their limited access to the hospital, which is far away from their home, and they cannot visit these facilities alone. However, the usage of mobile phones for acquiring family planning information was mentioned only by two respondents as they use mobile phones for searching for contraceptive injections, their dosage and side effects.

"I use google to find home remedies for sexual issues because I cannot go to the public hospital and it is a most convenient way to get help while staying at home" (A woman from Gadap Town)

\section{Current experience related to family planning}

Women showed a positive attitude towards family planning. The major reason for using the family planning method was "poverty", as they cannot afford the education, food and resources are limited.

'I don't want to have more children, my husband is a worker in a factory and we don't have enough money to raise children. My husband asked me to do family planning and that's why I am using it (A woman from Azam Basti)

To understand women's autonomy for using the family planning method, questions about authority to decide

for family planning were asked. Most of the respondents mentioned that it was a "mutual decision". However, a few discussed that they are using it without telling their husband or in-laws, but all of the respondents highlighted that they can't decide on their own, as the consensus of the husband is considered very important.

Respondents from both sites considered transport cost a major issue for availing of family planning services. Additionally, long waiting time and providers behaviour with the client was also considered as barriers to avail family planning services. Incomplete or no information (poor counselling) during the time of service delivery was another barrier discussed during interviews. 
'The nurse at the facility didn't tell me much about the method, when I went there to receive services, she gave me implant without explaining anything' (A woman from Gadap Town)

Women's perception was also explored for the source of information of family planning, where few women discussed LHW as a source, but many stated peers/ friends, the facility near their home, and midwives working in the communities. Respondents highlighted that the complete information including side effects is not provided at the facilities, which is a significant gap.

'The providers at the facilities, are not giving complete information on side effects, which they should because women who use an implant or IUCD needs to go far away for removal of these methods' (A woman from Gadap Town)

II. Acceptability of potential mHealth application: This broader theme covered the perceived acceptability of a potential mHealth application for family planning, which includes the preference for language, features, and information that needs to be included as a salient feature of the application to meet the demand for family planning. Though no application has been developed yet, the idea of a mobile application for family planning was explained to both women and providers, where similar applications from other countries were used for providing information to the clients (23) were shown to the women and providers.

\section{Information}

This probe explored women's and providers' perceptions of the kind of information that needs to be included in the application. Several suggestions were discussed during the interviews, almost all the respondents insisted to include 'complete information on all family planning methods. The term complete information was defined as the information about every family planning method; including its dosage, the benefit of every method, potential side effects, and ways to manage side effects at home. A few providers suggest including the social advantage of poverty reduction as a benefit of family planning to convince people living in low-socioeconomic areas to use contraception. The majority of respondents also suggested adding information about common misconceptions, as well as information about the facilities that provide services for method removal. Most of the women mentioned that there was no need for putting information about family planning facilities, as they know where to go for these services. Surprisingly, a few providers suggested not to include information on side effects in the potential application

'Don't put information about side effects, it will discourage woman and she won't use the method' (An LHV from Azam Basti)

\section{Language}

The respondents of this study belong to low socio-economic areas where the literacy level is very low. Most of the women preferred to have content in the local language (Urdu) because many women in those communities can easily read Urdu. However, a few women in Gapad Town considered including Sindhi (another local language) in addition to Urdu for the content in the application.

\section{Features}


All respondents were well aware of the different features of the mobile phone application. Short videos for providing family planning information about; methods, usage, advantages and side effects were the most recommended features of the application by the women. According to the respondents (both women and providers), short videos are easy to understand, especially for women who are illiterate and cannot read the content. A few respondents also suggested putting pictures in the app.

\section{Perceived benefits by women}

Several benefits were discussed during the interviews. The most important benefit was saving transport costs, which was discussed highly by the women.

'If I get all the information at home, I don't need to spend money to go to the facility which is far away, sometimes we go there just to get information only' ( $A$ woman from Gadap Town)

'Once I went to the clinic the doctor told me about the IUCD, I didn't get the service because I have to think about it, and need to discuss it with my husband. This application will save my money for such trips' (A woman from Azam Basti)

Another discussed benefit was filling the information gap for family planning. According to women, most of the time LHWs working in the area don't have complete knowledge about the family planning method, therefore they don't respond to women's queries. This application will be helpful to LHWs as well. 'There are many things which LHWs and health workers don't know. This application will increase their knowledge as well' (A woman from Gadap Town)

'We have a gathering of married women in our community, if this information is available through the application we can discuss it with each other and increase knowledge about family planning method among women of our community (A woman from Gadap Town)

\section{Perceived benefits by providers}

The perceived benefits were different for providers as compared to women. The most important benefit was saving providers time at the health facility. The majority of providers were discussed as those women who will use application and will come prepared to the facility for a specific method, which will save provider's time to counsel women for the specific method.

'If women already have all the knowledge about the family planning method including side effects and benefits, she will come with a decision about the method, and this will save my time of counselling and convincing women about using that method' (A provider from Gadap Town)

A few providers also considered that the potential mHealth application will save providers time because they will stay at the facility due to a large number of clients for family planning.

'The client flow is high in our facility, sometimes we have to stay longer to the facility. This application will reduce our time and make our work easy' (A provider from Azam Basti)

\section{Self-efficacy}


is related to the perception of respondents about increasing empowerment by making the decision on their own, less dependent on community workers, and increase self-confidence.

It was important to explore women's understanding of empowerment. All the women unanimously considered deciding on their own about family planning method as an indicator of empowerment. However, these women emphasized that decision making for contraception usage should be a "mutual" of the husband and wife, but explaining the method to their husband along with all the advantages and disadvantages was assumed to be a difficult task. According to women, this application will help them to decide as they will receive all the information and can communicate with their husbands confidently.

'When I start using injection I and my husband were confused because of all the misconceptions, this application can help me to understand all the potential benefits and harms of the method. I can even show it to my husband to make him understand as well' (A woman from Gadap Town)

Women also discussed the potential of application for reducing their dependency on community workers.

'The LHW in my area told me that pills are not suitable for me, but when I went to the clinic she (doctor) gave me pills. You know these community workers don't have complete knowledge. This application can help women (like me) to be more independent and less relying on LHWs' (A woman from Gadap Town)

Overall, the perception of the respondent for self-efficacy is associated with self-confidence. According to women, the application will increase their ability as well as reduce their dependency on health workers for providing information about the contraceptive method, which will eventually increase their self-confidence for making decisions about the method which (according to them) is more suitable for them.

\section{Discussion}

The overall goal of this study was to explore the feasibility and acceptability of mHealth technology for increasing the uptake of family planning among women living in low socio-economic areas of Karachi. There are several studies conducted in low and middle-income countries to understand the impact of the mHealth intervention on contraceptive usage $(24,25,26,27,28)$. Keeping in view that smartphone usage has been increased five times since 2014 to 2020 (from 10\%-51\%) (29)(19), the potential for using the mHealth strategy in Pakistan for increasing uptake of family planning has also increased. This research informs that the mHealth intervention can be considered feasible if the family planning information provided to the women is complete and accurate. The mobile application for family planning also seems to increase women's selfefficacy by increasing their confidence for family planning decisions.

During this exploratory study, women expressed enthusiasm for using the mHealth application for family planning in the future and emphasized including complete information about family planning methods in the app to increase its acceptability. Providing complete information about family planning methods is a fundamental right of the individual (30). A study in a similar setting discussed that 'word of mouth is the main source of information on family planning in rural areas of Pakistan (31). The participants of our study suggested including information about side effects for every method is important. A study on the development and testing of contraceptive counselling app "miPlan" also considered providing information on side effects 
and the contraceptive failure rate is an essential feature of the mobile application(32). Research on using mobile applications for increasing the uptake of postabortion contraception in Cambodia discussed that the mHealth intervention helped women to retain information about postpartum family planning contraception, which was difficult before the mHealth intervention (33). However, the perception of providers in this study regarding the benefits information was different than the users; they insist on considering family planning usage a poverty reduction tool. Evidence suggests that family planning intervention increases women's status and reduces poverty (34).

Women and providers discussed several barriers and challenges during this study for utilizing family planning services at the facility level. One of the important perceived challenges by women is travelling cost, which most of the time they bear for just to get information about family planning method, women suggested that they will save this cost by receiving all the information at home. Literature indicates that mobile health interventions in family planning are considered the best cost-effectiveness strategy for LMICs $(36,37)$. Poor counselling by the provider is another barrier discussed during this research, and mHealth application is considered as the best solution to overcome this obstacle. Several mobile applications such as M4RH(37), D-tree(38), and iMACC(39) are introduced for providing complete and comprehensive counselling to the users through community workers. Comprehensive counselling needs providers adequate time, it is an essential factor for user satisfaction towards contraceptive methods. In this study, the provider mentioned the mHealth intervention as a time-saving strategy for them, as women already have all the information about the contraceptive methods which will save the provider's time to counsel and convince women for the contraceptive methods. Furthermore, the evidence shows that the family planning application saves counselling time for the providers(39). Similarly, mHealth interventions in family planning increase women's ability to decide on the contraceptive method of their choices, which helps to narrow the knowledge gap of community health workers for the family planning method. The participant of this study felt that the majority of lady health workers don't have adequate knowledge of family planning methods, mHealth intervention can fill this gap. In addition to that, complete information about methods including side effects can help women to make decisions on their own.

mHealth increase women empowerment through knowledge gain, decision-making and economic stability (40). Though participants in our study felt that family planning decisions should be mutual, and consensus should be made by both husband and wife, but they indicated that with complete information about the family planning methods, they can convince or explain their husbands for adopting a specific method. Decisionmaking power is directly linked with the knowledge of contraception. A study conducted in Africa indicates that decision making power for family planning use was higher in those women who have adequate knowledge of family planning (41). The participants in our study also agreed that the knowledge of family planning would increase their self-confidence for the contraceptive method. Evidence also suggests that mobile interventions increase women's decision making and empowerment(42). mHealth solutions can provide a better understanding of family planning methods and can change women's cognitive behaviour towards using modern contraception.

This was the first exploratory study conducted to assess the feasibility of mHealth interventions using women's perceptions living in low socio-economic areas of Karachi. Though mobile phone interventions have been experienced in the field of immunization in Pakistan $(43,44)$, the mHealth strategy has yet to be implemented in the area of family planning in the country. Provider's perspective for the mHealth intervention helped to

Page $14 / 19$ 
triangulate the qualitative data of this study. There is a need for quantitative exploration to quantify the finding of this study. The diverse population of two selected sites of Gadap town and Azum Basti increases the generalizability of this study with a similar setting, but the findings cannot be generalized to the rural areas, where smartphone usage is very low. However, participants of this study were women who own smartphones or use their husband's phone, the perceived benefit of the mHealth intervention was not analysed separately. To assess the perceived benefits of mHealth interventions for uptake of family planning, it is suggested to conduct interventional studies. Further focus group discussion was planned previously with the women living in low socio-economic areas, later due to the COVID situation, those focus groups were converted into in-depth interviews.

\section{Conclusion}

mHealth intervention could answer many challenges that the family planning services provision is facing in Pakistan. High penetration of mobile phone among women open venues for cost-effective intervention that can reduce the knowledge gap and address cultural barriers in the country for family planning services. The major benefit of the mHealth strategy is that it will help to increase women's self-confidence for choosing and deciding about the family planning method. The next step is to implement such an intervention for family planning to identify the impact on the larger population for family planning uptake.

\section{List Of Abbreviations}

FP Family Planning

iMACC Mobile Application for Contraceptive Choice

LMIC Low and Middle Income Countries

LHV Lady Health Visitors

LHW Lady Health Workers

M4RH Mobile for Reproductive Health

\section{Declarations}

Ethical Approval: The study was approved by the Ethical Review Board Aga Khan University (ERC\# 2020-35458977). All methods were performed according to the "Declaration of Helsinki" in accordance with the ethical guideline and regulations.

Consent to Participants: the written consent (signature) was obtained from the participants who are can read and write, while those who cannot write a thumb impression was obtained. The purpose of the study was explained to all the participants. The question asked by the participants were answered and explained until they feel satisfied. It was also explained to the participants that they have the right to leave the interview at any time, whenever they feel uncomfortable or don't want to answer any further questions. Contact of Principle 
Investigator (email and phone number) was shared with the participants in case they have any queries related to the research.

Consent for publication: The participants of this study provided permission for sharing the results of this study for publication.

Availability of data and material: All the data (used and analysed) in this study are available from the corresponding author on request.

Competing interest: The authors declare that there is no competing interest for this study.

Funding: The study is funded by the Department of Community Health Sciences, Aga Khan University.

Author's Contribution: FGA, RI and SS were involved in conceptualizing and designing the study. FGA collected data, conducted initial analysis and write the first draft of the manuscript. FGA, SS and RI contributed to data analysis, manuscript writing and approval of the final draft.

Acknowledgements: We are very thankful to the women and family planning providers for their time and views provided for this study.

\section{Author's Information:}

Farina Gul Abrejo is an MSc in Health Policy and Management, affiliated with the population and reproductive health section at the Department of Community Health Sciences, Aga Khan University.

Dr Romaina Iqbal is an Associate Professor and a section head for Non-Communicable Diseases at the Department of Community Health Sciences, Aga Khan University.

Dr Sarah Saleem is a Professor and section head for Population and Reproductive Health at the Department of Community Health Sciences, Aga Khan University.

\section{References}

1. Mobile Health - an overview. ScienceDirect Topics. https://www.sciencedirect.com/topics/medicine-anddentistry/mobile-health. Accessed 31 August 2021.

2. Bastawrous A, Armstrong MJ. Mobile health use in low-and high-income countries: an overview of the peerreviewed literature. Journal of the royal society of medicine. 2013;106(4):130-42.

3. Gogova T, Milavec Kapun M, Parreira P, Kvas A, Santos-Costa P. Patient empowerment with mHealth apps. 2018 Jan 1

4. Alhomod AS, Alzahrani S. Patient Empowerment via Mobile Personal Health Records and Mobile Health Applications: A Review of the Current Use. In IEEE; 2019. p. 1-4.

5. Mobile phones empower women in developing world - Oxford study. University of Oxford. https://www.ox.ac.uk/news/2020-06-08-mobile-phones-empower-women-developing-world-oxford-study. Accessed 8 September 2021. 
6. Digital Health for Social and Behavior Change. HIPs. http://fphighimpactpractices.org/briefs/digital-healthsbc/. Acessed 8 September 2021.

7. Diamond-Smith N, Warnock R, Sudhinaraset M. Interventions to improve the person-centred quality of family planning services: a narrative review. Reproductive health. 2018;15(1):1-17.

8. Aung B, Mitchell JW, Braun KL. Effectiveness of mHealth interventions for improving contraceptive use in low-and middle-income countries: a systematic review. Global Health: Science and Practice. 2020;8(4):813-26.

9. Hill J, McGinn J, Cairns J, Free C, Smith C. A Mobile Phone-Based Support Intervention to Increase Use of Postabortion Family Planning in Cambodia: Cost-Effectiveness Evaluation. JMIR mHealth and uHealth. 2020;8(2):e16276.

10. Smith C, Gold J, Ngo TD, Sumpter C, Free C. Mobile phone-based interventions for improving contraception use. Cochrane Database of Systematic Reviews. 2015;(6).

11. Ahmed H. 75\% of People in Pakistan Own a Mobile Phone: Report. https://propakistani.pk/2020/02/18/75of-people-in-pakistan-own-a-mobile-phone-report/

12. Pakistan: smartphone penetration. https://www.statista.com/statistics/671542/smartphone-penetrationas-share-of-connections-in-pakistan/. Accessed 1 September 2021

13. Mawani M, Kadir MM. Use of M-Health Technology for Preventive Medicine in Pakistan. 2016.

14. Pakistan Demographic \& Health Survey, 2017-2018 [Internet]. 2019. https://www.familyplanning2020.org/resources/pakistan-demographic-health-survey-2017-2018. Accessed 1 September 2021.

15. Feroz A, Rizvi N, Sayani S, Saleem S. Feasibility of mHealth intervention to improve uptake of antenatal and postnatal care services in peri-urban areas of Karachi: a qualitative exploratory study. J Hospit Manage Health Policy. 2017;4(1):1-11.

16. Smith C, Vannak U, Sokhey L, Ngo TD, Gold J, Free C. Mobile Technology for Improved Family Planning (MOTIF): the development of a mobile phone-based (mHealth) intervention to support post-abortion family planning (PAFP) in Cambodia. Reproductive health. 2015;13(1):1-8.

17. Dev R, Woods NF, Unger JA, Kinuthia J, Matemo D, Farid S, et al. Acceptability, feasibility and utility of a Mobile health family planning decision aid for postpartum women in Kenya. Reproductive health. 2019;16(1):1-11.

18. Johns Hopkins Center for Communication Program. Health Communication Component (HCC) Maternal and Child Health (MCH) program.

https://www.thecompassforsbc.org/sites/default/files/project_examples/mHealthLHWPReport_FINAL.pdf. Accessed 3 September 2021.

19. GSMA. Addressing the mobile gender gap in Pakistan [Internet]. 2021. Available from: https://www.gsma.com/mobilefordevelopment/wp-content/uploads/2021/04/Addressing-the-MobileGender-Gap-in-Pakistan.pdf

20. Guest G, Bunce A, Johnson L. How many interviews are enough? An experiment with data saturation and variability. Field methods. 2006;18(1):59-82.

21. Fusch PI, Ness LR. Are we there yet? Data saturation in qualitative research. The qualitative report. 2015;20(9):1408. 
22. Rawlett KE. Journey from self-efficacy to empowerment. Health Care. 2014;2(1):1-9.

23. Family Planning. Hesperian Health Guides. https://hesperian.org/books-and-resources/our-mobileapplications/family-planning/. Accessed 16 September 2021.

24. Lemay NV, Sullivan T, Jumbe B, Perry CP. Reaching remote health workers in Malawi: baseline assessment of a pilot mHealth intervention. Journal of health communication. 2012;17(sup1):105-17.

25. Johnson D, Juras R, Riley P, Chatterji M, Sloane P, Choi SK, et al. A randomized controlled trial of the impact of a family planning mHealth service on knowledge and use of contraception. Contraception. 2017;95(1):90-7.

26. Harrington EK, McCoy EE, Drake AL, Matemo D, John-Stewart G, Kinuthia J, et al. Engaging men in an mHealth approach to support postpartum family planning among couples in Kenya: a qualitative study. Reproductive health. 2019;16(1):1-11.

27. Laidlaw R, Dixon D, Morse T, Beattie TK, Kumwenda S, Mpemberera G. Using participatory methods to design an mHealth intervention for a low income country, a case study in Chikwawa, Malawi. BMC medical informatics and decision making. 2017;17(1):1-12.

28. Gurman TA, Rubin SE, Roess AA. Effectiveness of mHealth behavior change communication interventions in developing countries: a systematic review of the literature. Journal of health communication. 2012;17(sup1):82-104.

29. Pakistan: smartphone penetration. https://www.statista.com/statistics/671542/smartphone-penetrationas-share-of-connections-in-pakistan/. Accessed 5 October 2021.

30. FP2020_Statement_of_Principles_FINAL.pdf [Internet]. [cited 2021 Oct 4]. Available from: https://www.familyplanning2020.org/sites/default/files/rights-basedfp/FP2020_Statement_of_Principles_FINAL.pdf

31. Mustafa G, Azmat SK, Hameed W, Ali S, Ishaque M, Hussain W, et al. Family planning knowledge, attitudes, and practices among married men and women in rural areas of Pakistan: Findings from a qualitative need assessment study. International journal of reproductive medicine. 2015;2015.

32. Akinola M, Hebert LE, Hill BJ, Quinn M, Holl JL, Whitaker AK, et al. Development of a mobile app on contraceptive options for young African American and Latina women. Health Education \& Behavior. 2019;46(1):89-96.

33. Smith C, Vannak U, Sokhey L, Ngo TD, Gold J, Free C. Mobile Technology for Improved Family Planning (MOTIF): the development of a mobile phone-based (mHealth) intervention to support post-abortion family planning (PAFP) in Cambodia. Reproductive health. 2015;13(1):1-8.

34. Allen RH. The role of family planning in poverty reduction. Obstetrics \& Gynecology. 2007;110(5):9991002.

35. Hill J, McGinn J, Cairns J, Free C, Smith C. A Mobile Phone-Based Support Intervention to Increase Use of Postabortion Family Planning in Cambodia: Cost-Effectiveness Evaluation. JMIR mHealth and uHealth. 2020;8(2):e16276.

36. Prinja S, Bahuguna P, Gupta A, Nimesh R, Gupta M, Thakur JS. Cost effectiveness of mHealth intervention by community health workers for reducing maternal and newborn mortality in rural Uttar Pradesh, India. Cost Effectiveness and Resource Allocation. 2018;16(1):1-19. 
37. Johnson D, Juras R, Riley P, Chatterji M, Sloane P, Choi SK, et al. A randomized controlled trial of the impact of a family planning mHealth service on knowledge and use of contraception. Contraception. 2017;95(1):90-7.

38. The David and Lucile Packard Foundation. Using Mobile Health Applications to Improve Family Planning Services [Internet]. The David and Lucile Packard Foundation. 2013 [cited 2021 Oct 5]. Available from: https://www.packard.org/awardee/m-health-improve-quality-family-planning-services-tanzania/

39. Dev R, Woods NF, Unger JA, Kinuthia J, Matemo D, Farid S, et al. Acceptability, feasibility and utility of a Mobile health family planning decision aid for postpartum women in Kenya. Reproductive health. 2019;16(1):1-11.

40. Jennings L, Gagliardi L. Influence of mHealth interventions on gender relations in developing countries: a systematic literature review. International journal for equity in health. 2013;12(1):1-10.

41. Dadi D, Bogale D, Minda Z, Megersa S. Decision-making power of married women on family planning use and associated factors in Dinsho Woreda, South East Ethiopia. Open access journal of contraception. 2020;11:15.

42. Dev R, Woods NF, Unger JA, Kinuthia J, Matemo D, Farid S, et al. Acceptability, feasibility and utility of a Mobile health family planning decision aid for postpartum women in Kenya. Reproductive health. 2019;16(1):1-11.

43. Rai T. Stepping Up Lady Health Worker (LHW) Program and Integrating the Electronic Immunization Record and Tracking System into the Program as a Pilot Project in the Underserved District of Quetta, Balochistan, Pakistan. Pakistan Journal of Public Health. 2020;10(3):133-9.

44. Zaidi S, Shaikh SA, Sayani S, Kazi AM, Khoja A, Hussain SS, et al. Operability, acceptability, and usefulness of a mobile APP to track routine immunization performance in rural Pakistan: interview study among vaccinators and key informants. JMIR mHealth and uHealth. 2020;8(2):e16081.

\section{Figures}

\section{Figure 1}

Theoretical framework of the study 